\title{
CIBERACTIVISMO Y NUEVOS MOVIMIENTOS URBANOS: LA PRODUCCION DEL NUEVO ESPACIO PÚBLICO EN LA POLITICA CONTEMPORÁNEA
}

\author{
Dr. Francisco Sierra Caballero \\ Universidad de Sevilla, Sevilla, España \\ fsierra@us.es \\ ORCID iD: https://orcid.org/0000-0001-7398-7588
}

Recibido el 29 de mayo de 2019

Aceptado el 13 de febrero de 2020

\section{Resumen}

En la era de la autocomunicación de masas, parece lógico revisar críticamente la metainvestigación en comunicación, la reflexividad dialéctica, recursiva y generativa del campo para recomponer las posiciones de observación, algo similar a lo que Zizek describe en Visión de Paralaje sobre cambios de objeto y posiciones de observador. Así se observa con el ciberactivismo, forma emergente de intervención que manifiesta modalidades y configuraciones subalternas del antagonismo y la autonomía de los sectores populares que deberían ser considerados en su radicalidad histórica marcada por la emergencia de procesos inéditos de lucha por la emancipación. En el presente trabajo, se propone un análisis conceptual de la tecnopolítica contemporánea, a partir de una lectura marxista, de la esfera pública emergente, como espacio público oposicional, en términos de estructura de clases. A partir de la deconstrucción de la posición de observación, pero también de la mudanza de objetos, que introduce la revolución digital, el trabajo aporta una lectura materialista de deconstrucción de las ideas convencionales sobre la cultura digital en la producción de las nuevas subjetividades políticas, abordando la realidad multidimensional de la función estructurante de la comunicación como un problema de articulación productiva con el proceso de cambio e innovación de nuestra realidad en virtud de la naturaleza de la nueva economía de la cultura.

Palabras clave: ciberactivismo, acción colectiva, redes de contrainformación, esfera pública, tecnopolítica, teoría marxista. 


\title{
CYBERACTIVISM AND NEW URBAN MOVEMENTS: THE PRODUCTION OF THE NEW PUBLIC SPACE IN CONTEMPORARY POLITICS
}

\begin{abstract}
In the era of mass self-communication, it seems logical to critically review the metaresearch in communication, the dialectical, recursive and generative reflexivity of the field to recompose the observation positions, something similar to what Zizek describes in Parallax Vision on object changes and observer positions. Cyberactivism manifests subaltern modalities and configurations of antagonism and autonomy of popular sectors that must be considered in their historical radicality. The complementarity of these categories accounts for a new culture and political subjectivation marked by the emergence of unprecedented processes of struggle for emancipation. In the present work, a conceptual analysis of contemporary technopolitics is proposed, from a Marxist reading, of the emerging public sphere, as an oppositional public space, in terms of class structure. Starting from the deconstruction of the observation position but also from the change of objects introduced by the digital revolution, the work provides a materialistic reading of the deconstruction of conventional ideas about digital culture in the production of new political subjectivities, approaching the multidimensional reality of the structuring function of communication as a problem of productive articulation with the process of change and innovation of our postmodernity by virtue of the nature of the new cultural economy.
\end{abstract}

Keywords: cyberactivism, collective action, networks, public sphere, technopolitics, marxist theory. 
Introducción

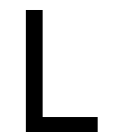

a centralidad del ciberactivismo, en los nuevos movimientos sociales, ilustra en nuestro tiempo la intensificación del antagonismo y el despliegue de formas autónomas de acción colectiva y organización social. Experiencias como Occupy Wall Street o el 15M demuestran la emergencia de nuevas formas de expresión de los frentes culturales marcada por un potente despliegue de mundos posibles en la medida que articula productivamente medios, pantallas, procesos orgánicos, infraestructuras y dispositivos envolventes para una ciudadanía activa en demanda de un rol determinante en las políticas públicas. En estos, como en otros movimientos de protesta, la autonomía, como anticipara Castoriadis, es un problema central, dado que, como señala Boaventura Sousa-Santos, cuestiona la relación entre Estado y sociedad civil, al irrumpir los nuevos movimientos urbanos en el espacio público desde la lógica creativa de constitución de esferas de deliberación autónomas e instituyentes (Sousa-Santos, 2016). En este sentido, podemos hablar de una producción autónoma del espacio y del régimen de representación frente al modelo dominante de reproducción social. Ello exige, en consecuencia, desde el punto de vista de la investigación, tratar de explorar el amplio abanico de prácticas, las formas de organización de la resistencia y de la cooperación social ampliada, que emergen con el activismo digital. Pues, entre otras razones, los nuevos movimientos urbanos modifican sustancialmente la topología y lógicas de intervención creando "sus propios lugares y escalas, su propia ciudadanía, que no se refiere en absoluto a la membresía de un Estado-nación u otra escala política preestablecida (sino más bien) a una ruptura del régimen escalar convencional y su orden vertical jerárquico, que se traduce tanto en la toma de la centralidad de la plaza emblemática, como en la descentralización hacia las asambleas de barrio. Esta inversión del orden de la jerarquía escalar del Estado, situando en primer lugar lo local-comunitario" (Díaz, Jover y Roca, 2017: 353) es la base de una lectura, otra de la mediación social. Desde otro punto de vista, algunos autores cuestionan la proyección social y la función explicativa atribuida a la noción de ciberactivismo por resultar improductiva al instituir "una separación entre unas actitudes activas y otras supuestamente pasivas en las redes, un universo en que todas las subjetividades interconectadas que cooperan son, de formas diferentes, productoras o reproductoras - por lo tanto, agentes activos - de conocimientos y formas de vida" (Condorelli y Gambetta, 2016: 12). Sin entrar ahora en este debate, que luego será abordado, lo cierto, en cualquier caso, es que en las dinámicas de las multitudes inteligentes es donde podemos hallar las claves de nuestro tiempo para comprender la política contemporánea. Una forma mediatizada tecnológicamente, que hace relevante para el análisis social el rol de la red de relaciones y las formas de acción colectiva que tienen lugar con las nuevas tecnologías de la información. De los indignados a las movilizaciones del Rif, el ciclo de protestas y emergencia de nuevos movimientos sociales ha tenido en los medios digitales una viva expresión que ha hecho posible tanto la autonomía como la experimentación de formas creativas de 
institucionalidad y participación ciudadana apuntando, en este sentido, de forma sintomática, a la vindicación de otro espacio e imaginario de lo común.

La hipótesis de trabajo de nuestro estudio es la constatación del reconocimiento de la necesidad de otra lógica de análisis de la mediación social. La crisis de confianza, en el origen de los nuevos movimientos urbanos, es, antes que nada, una crisis de representación por ineficiencia y colapso del modelo de gobernanza liberal. Las movilizaciones de los indignados ("¡No nos representan!") evidencian, por ello, en primer término, los límites institucionales establecidos ante la ruptura del contrato social por las quiebras y fracturas de la crisis del capitalismo, abriendo así una brecha casi insalvable entre ciudadanía y representantes políticos, tal y como hoy se puede observar en las protestas de los chalecos amarillos en París. En este proceso, la crisis de legitimidad política afecta sobremanera al poder y estructura mediática. "La globalización de la economía y de la comunicación ha socavado y desestructurado las economías nacionales y limitado la capacidad del Estado-nación a responder en su ámbito a problemas que son globales en su origen, tales como las crisis financieras, los derechos humanos, el cambio climático, la economía criminal o el terrorismo. Lo paradójico es que fueron los estados-nación los que estimularon el proceso de globalización, desmantelando regulaciones y fronteras desde la década de los ochenta, en las administraciones Reagan y Thatcher, los dos países líderes de la economía internacional entonces. Y son esos mismos estados los que están replegando velas en este momento, bajo el impacto político de los sectores populares que en todos los países han sufrido las consecuencias negativas de la globalización" (Castells, 2017: 20). La emergencia de esferas públicas alternativas y proletarias, en el sentido etimológico del término, que Kluge y Negt describen en "Esfera pública y experiencia: hacia un análisis de la esfera pública burguesa y proletaria" (1993) apuntan en este sentido a la pertinencia de una lectura materialista poco o apenas explorada en la literatura especializada en la materia. La investigación en comunicación no se ha replanteado, por lo general, las nociones al uso de espacio público ante las nuevas formas emergentes de intercambio. La lectura prevaleciente del $15 \mathrm{M}$ y el ciclo de protestas protagonizados por los nuevos movimientos sociales como Yo soy 132 se ha definido en términos postmaterialistas desde una lectura culturalista de la identidad nada adecuada a la naturaleza de los procesos de transformación en curso.

Con Lévy (2002) a Downing (2001), pasando por Coleman (2014), es posible observar que los nuevos movimientos sociales proyectan un tipo de articulación o espacio alternativo, en la medida que constituyen "comunidades especializadas, gobernadas por un sistema de valores propio y una legalidad autónoma, que suelen fomentar prácticas de resistencia o de oposición frente a la sociedad hegemónica" (Pecourt, 2016: 135). Los medios de contrainformación configuran, desde este punto de vista, un espacio de autonomía. "Hablamos de una esfera pública periférica que, al margen o muy alejada de los centros de poder, cobró una relevancia inusitada ante la parálisis de la esfera pública central, formada por los medios convencionales y las fuerzas políticas" (Sampedro, 2005: 19). Más aún, los 
espacios públicos de la galaxia Internet se han multiplicado con los puntos de acceso, los pasajes wifi, los callejones virtuales y los no lugares o espacios de tránsito. Desde este punto de vista, como advierte Castells, además de generar nuevas ágoras virtuales, movimientos como el $15 \mathrm{M}$ desplegaron una auténtica guerrilla cultural en múltiples espacios y redes de intercambio dando lugar a una nueva cultura política que, por principio, impugna el modelo dominante de mediación social. "En esta dinámica, el empoderamiento de los procesos comunicacionales autónomos se ha percibido como una necesidad, como canales de expresión en la dinámica de la movilización y la organización popular. Incluso bajo el control y el poder de coacción (...), en su fase de declive y corriendo todos los riesgos de la coyuntura política (el estado de excepción y sus mecanismos de represión), los movimientos sociales populares y otras organizaciones progresistas se atrevieron a crear canales alternativos para comunicarse. Ejercieron (y continúan ejerciendo) el derecho a comunicar en la práctica, tanto usando medios alternativos como una forma de escapar al control y la represión policiales como enfrentando disposiciones legales" (Peruzzo, 2016: 18).

El presente trabajo avanza una propuesta conceptual que, desde la teoría crítica, contribuya a redefinir procesos en curso como el movimiento de protesta de los chalecos amarillos desde un análisis estructural y económico-político de la teoría social de la mediación que aborde tanto la dimensión estética y expresiva como la estructura de reproducción en la que tienen lugar estos procesos de intervención social. Tal y como trataremos de demostrar, los actuales procesos de movilización y acción colectiva en red no solo tienen su origen en factores materiales y de justicia social, en términos de lucha de clases, sino más allá aún, tales dinámicas plantean un problema de hegemonía en la dialéctica del Estado y la sociedad civil, desde el punto de vista de la reproducción ideológica. Considerando la naturaleza antagonista y autogestionaria de los nuevos movimientos urbanos, el estudio del ciberactivismo pasa, en este sentido, por poner el acento en la latente contradicción entre democracia formal representativa y espacio alternativo concebido este, como trataremos de demostrar, en términos de Espacio Público Oposicional (EPO). En particular, en las siguientes páginas, se va a formular una primera aproximación materialista para interpretar las nuevas formas de acción colectiva en torno al concepto de Esfera Pública Oposicional de Oskar Negt. A tal fin, definiremos los elementos distintivos de participación y autonomía de la cultura digital en las formas contemporáneas de activismo digital, al tiempo que se apuntan algunos rasgos distintivos de las formas de participación y organización social que justificarían la pertinencia de esta lectura al tratar de comprender, desde una perspectiva relacional, las formas de acción colectiva en la tecnopolítica contemporánea.

\section{Estado del arte}

El estudio del ciberactivismo, como el de todo proceso de movilización y acción colectiva, puede ser abordado desde el campo habitual de las formas de resistencia 
cultural y la confrontación político-ideológica o como proceso de innovación desde el punto de vista organizativo. Ahora bien, el análisis de la mediación social debe de considerar, necesariamente, tanto la dimensión material (necesidades básicas) como el campo simbólico de antagonismo o disputa del sentido. El código, como sabemos desde Lévi-Strauss (2006), presupone vínculo social, conectividad y lógica de la mediación constituyente de la cultura. Las metáforas de puentes, redes, canales y puertas o ventanas abiertas a la realidad que siempre han popularizado los estudios en comunicación dan cuenta de la centralidad de la articulación de los espacios físicos y virtuales de mediación. De acuerdo con esta idea, comprender las formas vigentes de captura y apropiación del capital, que atraviesan y colonizan los distintos tipos de relación, el lenguaje y los afectos de la cultura-red y el modo de producción postfordista, exige prestar mayor atención al campo de la comunicación como un vector central del proceso de acumulación por desposesión, asumiendo desde luego, necesariamente, el rol constituyente que tiene en la configuración de los actuales sistemas complejos, abiertos y heterotópicos del tardocapitalismo, o capitalismo maduro, a partir de nuevos abordajes teóricometodológicos en la materia que nos ocupa. Partimos para ello de una hipótesis complementaria con la que iniciábamos el artículo: el ciberactivismo hoy es una revuelta de la imaginación ante el colapso de las estructuras de dominio que permite la emergencia e insurgencia de los actores locales. Las nuevas formas de protesta constatan una crisis radical de la representación. "Las irrupciones que desobedecen el canon moderno que se atribuye a las revueltas, brillantemente enumeradas por Benson, han venido a desestabilizar el monopolio de la representación de lo real, disputando, mediante la tecnopolítica, el poder hacerver, hacer-creer de las narrativas dominantes que anulan o dificultan las posibilidades de autorrepresentación para los ciudadanos y, lo que es más importante: a través de este sistema multipolar, obligan a los medios convencionales a incorporar temas, asuntos, informaciones que transitan de la red a la calle y viceversa, un logro no menor" (Reguillo, 2017: 123). El rediseño acelerado de las formas de expresión del sujeto con las narrativas transmediales, la extensión identificativa de las marcas en el mercado, el interfaz de la realidad aumentada, y otras formas propias de la cibercultura, dibujan un contorno, en la era digital, que debe ser analizado reflexivamente, cuestionando las formas de dominio del habitus y los códigos culturales, a partir de ciertos patrones estéticos normalizados de los que depende el proceso de valorización en la medida que los nuevos movimientos urbanos cuestionan las matrices conceptuales para proponer un nuevo espacio público oposicional. Pensar esta dimensión es vindicar el antagonismo, en clave gramsciana, como una manifestación o modalidad de resistencia contra la hegemonía, distintiva del ciberactivismo, en tanto que frente cultural en el que tiene lugar la disputa del sentido. El proceso de reconstitución de la esfera pública es un proceso continuo de resistencia, emergencia, ebullición y repliegue en el que los dispositivos y plataformas digitales son nodos que articulan nuevas mediaciones sociopolíticas. Ello exige pensar la relación entre acción colectiva, estructura real de la información y cambio social. En otras palabras, es preciso analizar las relaciones entre agencia y formas institucionales de 
reproducción, recuperando los niveles y planos intermedios de determinación. "Concentrar la atención en dichas combinaciones - entrecruzamientos, desplazamientos - captura la acción de lo político tanto en su faz destituyente/deconstructiva/disruptiva/revolucionaria como en su despliegue constituyente/ordenador/instituyente/reproductivo. Tales momentos atraviesan la auto-producción de los sujetos y la reconfiguración de los órdenes sociales" (Modonesi, 2015: 46). En otras palabras, pensar hoy la cultura digital es pensar la psique individual, los imaginarios colectivos, tanto como la economía política de la comunicación desde una perspectiva praxiológica atenta a las estructuras y procesos más amplios de transformación del horizonte histórico del capitalismo.

Ello pasa, a nuestro modo de ver, por descartar el compromiso con la objetividad intelectual que impregna la tradición ilustrada y positiva de Marx, y sus discípulos, y develar o definir el sentido de todo constructo ideológico, que es mucho más que una lectura reduccionista del marxismo como análisis histórico-contextual de las condiciones de producción de todo texto, cuando sabemos que, en esencia, la revolución teórica de Marx es la dialéctica del pensamiento relacional. Desde este punto de vista, la historia de la Comunicación Participativa, pero también de las lecturas heterodoxas y creativas que procuraron transitar por ejemplo desde el marxismo otros caminos y derroteros negados por omisión o voluntad de poder de la Comunicación como Dominio, ha de ser, necesariamente, un punto de partida para analizar nuevos fenómenos como el ciberactivismo. Pero este no ha sido el criterio habitual en la investigación en comunicación, bien por olvido de la historia y las continuidades que, en todo proceso, también en lo relativo a la mediación social, tiene lugar, o por la prevalencia del paradigma funcionalista y sus epígonos de los Estudios Culturales. Así, en la literatura especializada en la materia, se observa una brecha de conocimiento y omisión sobre la géneris de las prácticas autónomas de articulación de voces con fines emancipatorios que el movimiento obrero y otras experiencias innovadoras del marxismo y sus organizaciones han venido desplegando como abertura contrahegemónica desde una crítica antagonista basada en la organización, la unidad y la autodeterminación, grupal y colectiva, que todos los movimientos sociales han procurado con fines liberadores. La lectura aquí propuesta es materialista, entendiendo el marxismo un campo teórico fecundo para ilustrar la acción colectiva del ciberactivismo como proceso de transformación histórico-social.

De acuerdo con Rancière (2010), las nuevas formas de protesta son interrupciones en la lógica de acumulación, en los dispositivos y procesos de dominio de los aparatos gubernamentales y de normalización, al alterar la acción, lo decible, pensable y visible. Desde este punto de vista, la oposición es una interferencia de la repetición, siguiendo con ello a Tarde (1986). Las interferencias pueden dar lugar a combinaciones o a conflictos de tipo antagonista. Las comunicaciones operan en la lógica de composición y potencialidad combinatoria que, en la cultura digital, amplían el margen de autonomía y acción de los sujetos. De acuerdo con Castells, estos movimientos, como el 15M, "construyeron un espacio de autonomía híbrido 
de lo real digital y de lo real urbano, como condición indispensable para encontrarse, reconocerse y buscar nuevas formas de relación política y utopía cultural de donde pudiera surgir una democracia distinta a las formas vacías y cínicas que ocupaban las instituciones sin control de los ciudadanos, con escaso respeto a los principios que proclamaban. Fue, en ese sentido, una expresión abierta de la crisis de legitimidad política latente tanto en España como en el resto del mundo" (Castells, 2017: 85). Desde este punto de vista, "el 15M sería el último ejemplo de una tendencia de la contestación política radical que adopta unas prácticas políticas autónomas. "Si para el marxismo la acción política desde abajo como vector de la politización de las clases subalternas es acción antagonista en estricto sentido, lo que tratamos de esbozar aquí son elementos de una teoría marxista de la acción antagonista en la que el adjetivo antagonista implica el reconocimiento de una característica o cualidad específica de la acción política" (Modonesi, 2016: 12). Ello implica tanto una crítica al concepto-fetiche del Estado, entendido como la reducción de lo político a la participación en las distintas escalas de las instituciones; como la propuesta de un marco de referencia alternativo, con un proyecto espacial propio fundamentado en la descentralización, la autogestión y autonomía de una escala local-comunitaria. "La adopción de este marco habría implicado la inversión del fetiche del Estado en un fetiche de lo comunitario, que idealiza una escala local y micro-local, donde se desenvolvería la comunidad inmediata, como único ámbito legítimo de la política. El contexto de crisis económica y emergencia social, unido al marco de oportunidades creado por la crisis de legitimidad política de los partidos mayoritarios, habrían evidenciado una falta de operatividad de este marco de referencia, conduciendo a una nueva inversión de planteamientos" (Díaz, Jover y Roca, 2017: 346).

En general, la emergencia de un espacio público oposicional depende de tres factores concomitantes:

- La articulación de los intereses subalternos.

- El intercambio y la motivación.

- Las tendencias destructivas propias de la desagregación de la esfera pública burguesa.

La pertinencia de un abordaje económico-político de las nuevas formas emergentes de participación y activismo digital en las redes sociales parte, en esta línea, como no podía ser de otro modo, de un contexto histórico general que explica procesos locales, cuyas formas de expresión y procesos de movilización colectiva suelen ser similares, con independencia del ámbito o entorno de proximidad. Esto es, no se puede entender procesos de crisis y contradicciones latentes que afloran en los nuevos movimientos urbanos sin ligar o correlacionar procesos, formas y dinámicas antagonistas que aparecen en lo local como resultado de la lógica general de despliegue del capitalismo y su proceso de acumulación por desposesión. La interpretación recurrente tiende, sin embargo, a incidir en la versión propia del determinismo tecnológico. La racionalidad instrumental explica así los nuevos 
movimientos urbanos como resultado de la expansión de las redes digitales. No hay un análisis comunicacional en términos de frentes culturales y lucha de clases. Así, no obstante, conceptos clave de la teoría marxista como la complejidad, la totalidad, la interacción y la distinción, entre otros, como alienación y antagonismo, son claves para comprender los nuevos procesos emergentes de ciberactivismo en la medida que tratan de pensar la articulación y regulación social del plano económico al político, y de la esfera o espacio público al ámbito productivo. La crítica de la Economía Política, como crítica de la ideología, define un campo de análisis central para comprender el proceso de reproducción social ampliada en la era Internet, desde este punto de vista. Más que nada porque no es posible pensar la tecnopolítica sin una crítica del espíritu del llamado capitalismo cultural. Tal lectura marxiana se justifica por la naturaleza de los nuevos movimientos de protesta, originados en su mayoría por la precariedad de los jóvenes urbanos, con condiciones salariales a la baja, escasas prestaciones, exclusión de la esfera pública $y$, en algunos casos, en situaciones de franca vulnerabilidad por la violencia y la muerte que acompaña al proceso de acumulación por desposesión. Así, el Informe World Protest demuestra que la mayoría de movilizaciones del actual ciclo de protestas responde a razones o causas estructurales de naturaleza económicopolítica. Desde el inicio de la crisis capitalista, el 2008, hasta nuestros días, las movilizaciones, más de 840 , en 84 países, se han concentrado en los países económicamente más avanzados por razones de justicia económica, pobreza y desigualdad (488 protestas), crisis de representación (376), justicia global (311) y defensa de los Derechos Humanos (302). Por otra parte, los cambios estructurales en los mundos de vida derivan de la forma de reproducción social que conviene tomar en consideración para encuadrar el análisis de las formas emergentes de acción colectiva propia de la cultura digital.

La lógica del capital es hoy la de la organización técnica de la producción en red. La web como consecuencia es un producto configurado por las matrices y dispositivos de valorización del capital. Por ello, hablar de ciberactivismo no es pensar la tecnopolítica desde lo social, sin más, sino más bien, por el contrario, comprender las mediaciones de la tecnología desde lo político, y el diseño e interfaz de lo digital como un problema de construcción social, de mediación, dialécticamente hablando (Fuchs y Mosco, 2017). Bien es cierto que, en Marx, y este fue el aporte de la Escuela de Frankfurt, no hay desarrollada una teoría de la mediación social que explique, conceptualmente, el dominio de la comunicación, y el control del espacio público, en la base de la oposición entre crítica de la economía política, lucha de clases y conflictos políticos y normativos que hoy percibimos como resultado de este despliegue y colonización de los mundos de vida. De tal carencia ya hemos hablado ampliamente en otro trabajo (Sierra, 2019). Ahora, desde una lectura de la autonomía de los nuevos movimientos urbanos, se puede analizar críticamente el ciberactivismo a partir de conceptos nucleares como el principio de conexión, la articulación, la hegemonía, la politicidad, la subjetivación política y la acción social mediada, consustanciales a la voluntad de autodeterminación, al resultar mucho más productivo tal universo categorial para 
ilustrar los cambios que se vislumbran en nuestras sociedades (Modonesi, 2016). En esta dirección, apunta justamente la obra de Oskar Negt y Alexandre Kluge, una de las escasas referencias que la literatura marxista ha aportado a la interpretación de los fenómenos de mediatización de la cultura moderna en el capitalismo.

En "Historie et subjectivité rebelle", Negt y Kluge reformulan de modo heterodoxo el núcleo conceptual del marxismo dando forma al sentido de espacio público proletario opuesto al sistema dominante de mediación, lo que nos lleva a problematizar las representaciones en las contradictorias y complejas dinámicas de la ambivalente lógica de la reproducción social, en el plano material y, desde luego, en el campo de lo simbólico. A partir del análisis sobre qué tipo de espacio, qué formas de interacción e intercambio tienen lugar en el dominio público y qué función mediadora tienen tanto los medios convencionales de información como hoy las redes sociales, la pertinencia de este marco teórico de referencia para pensar el ciberactivismo en tales términos, se antoja del todo oportuna y consistente, desde el punto de vista de la relevancia de las preguntas y abordajes aportados, fundamentalmente con relación a la distinción de las formas disímiles de organización de la mediación social conforme a la dinámica y estructuración de la reproducción de la sociedad de clases.

Si consideramos experiencias de largo recorrido como el $15 \mathrm{M}$ en España o el movimiento Occupy Wall Street, observamos que ambas tienen en común que implicaron una alteración radical de las condiciones de enunciación y representación del espacio público, tanto en el plano virtual como desde luego físicamente. La problematización de la relación entre espacio público (físicamente) y esfera pública (plano virtual, simbólico) está en la base del objeto de discusión de la tradición materialista desde Marx. Toda tecnología como producto cultural es fruto de una mediación objetivadora y una voluntad subjetiva. Esta articulación interna no es escindible, salvo analíticamente. Desde una lectura estructural, y considerando el contexto histórico, como Marx explicara a propósito del fetichismo de la mercancía, la lógica de valorización es la causa explicativa que ilustra la tendencial proyección o imagen ilusoria (en nuestro tiempo las fantasías electrónicas de cierto clickactivismo), como dinámica objetiva de realización. La lógica mercantil, en otras palabras, opera en el plano subjetivo y en la forma material de reproducción. Por lo mismo, la antagónica lectura de lo real y lo virtual, como realidades desconectadas, no es sostenible. Bien es cierto que, como recuerda Pedro Ibarra, "las manifestaciones en la calle son acciones radicalmente tradicionales. Asumen uno de los rasgos característicos - e históricamente constantes - de una de las formas clásicas de la acción colectiva: los movimientos sociales. Porque las manifestaciones no sólo tienen una virtualidad instrumental o identitaria, sino cuasi constitutiva de los movimientos sociales" (Grau e lbarra, 2004: 7). En esta línea, el ciberactivismo conecta en los nuevos movimientos urbanos con la necesidad de expresión, con la identidad. Ahora bien, todo movimiento social se proyecta en el espacio público al definir su diferencia y hacer visible su vindicación, indistintamente en la calle o en la red. La frontera entre lo virtual y lo real es un reto, 
en fin, de producción de la ciudadanía en la crisis de representación y desafiliación que vive la democracia formal representativa (Robert Castel dixit). En este sentido, cabe señalar que aquellas teorías que idealizan la necesaria doble articulación de forma separada terminan por sobredimensionar la autonomía de la comunicación o el lenguaje. Es el caso de la Teoría de la Acción Comunicativa de Habermas. El sistema teórico de Habermas no alcanza a explicar la nueva ecología cultural, la transnacionalización de la esfera pública mediatizada ni los procedimientos reales y concretos de participación y deliberación a nivel no solo del discurso. La Teoría de la Acción Comunicativa y la lógica de deliberación propia de la cultura republicana elude la estructura de clases y como ideal omite las contradicciones dinámicas de confrontación de la democracia deliberativa, sin contar la inviabilidad del diálogo a nivel macro y, como advirtiera Przewoski, Habermas considera la experiencia a nivel individual y el espacio público relegado a la lógica racional. Negt y Kluge retoman, en línea con Benjamin y Kracauer, una lectura centrada en el sujeto. "La visión de Habermas centrada en la esfera pública burguesa le impidió separar la significación de otras formas de actividad y discursos públicos excluidos u opuestos a los burgueses. De hecho, Habermas, en el prefacio de su célebre libro, se refiere a otros tipos de publicidad como variantes del tipo de publicidad burgués, mostrando de ese modo la falta de interés para también analizarlos intrínsecamente" (Roldán, 2017: 69).

Por ello, las tesis del EPO empiezan por formular una crítica de la esfera pública burguesa y la idea kantiana de república de los sabios, lo que implica otra lectura radicalmente distinta del intercambio y el proceso comunicacional y las tensiones o contradictorias dinámicas de acceso y control que atraviesan el campo de lo social.

Frente al idealismo comunicacional, Oskar Negt destaca las formas de deliberación, reconocimiento y antagonismo de las clases dominadas:

"La conscience collective, qui est le produit d'une coexistance entre les structures identitaires du moi, des déchirures du moi (éclats) et de la nation (ou plutôt de sa decomposition et de son carectère inachevé), s'affireme a travers deux processus distincts et antagoniques, par une face représentative et une face prolétarienne. Ce type de processus ne peut produire qu'une fausse conscience" (Negt, 2007: 21).

Por espacio público proletario cabe definir aquí aquel dominio público en cuyo seno los sujetos dan forma, como sujetos de la infrapolítica, a su expresión, intereses y aspiraciones existenciales. Comprende el conjunto de dimensiones sociales, experiencias, formas y características esenciales que son específicas de los grupos oprimidos (Negt, 2007: 38). Desde este punto de vista, no es posible separar vida material y significado, menos aún para una crítica de la mediación social. Igualmente, como advierte Balibar, cabe formular una crítica de ciertas lecturas marxistas dominantes al interpretar los procesos de representación que han privilegiado una concepción abstracta, y formal, de la ciudadanía (Balibar, 2004). Así, la imagen e imaginario del espacio público tiende a presentársenos como algo 
fijo y estático cuando sabemos, desde una perspectiva histórica, que las instituciones y formación del dominio público varía a lo largo del tiempo y en diferentes sociedades.

El espacio público es tanto lugar como proceso de apropiación social con la que organizamos nuestra experiencia del mundo. En este sentido, es preciso "entender la localidad no como una estructura espacial, sino como una estructura de sentimiento (...) (Desde este punto de vista), la imaginación no es una práctica individual de escape de la realidad, sino, por el contrario, una herramienta colectiva para la transformación de lo real, para la creación de horizontes múltiples de posibilidad" (Reguillo, 2017: 98). La apropiación presupone a este respecto un uso estratégico, político y creativo de las nuevas tecnologías. Pensar en términos de frentes culturales, nos lleva a redefinir, por consiguiente, la institucionalidad y los modelos organizativos de la sociedad civil tratando radicalmente al menos cuatro dimensiones centrales:

- La dinámica colaborativa o cooperación social.

- La visibilidad y alcance de las redes.

- La capacidad de movilización.

- La autonomía y reflexividad social de los actores colectivos.

La mediación, desde este punto de vista, es el proceso por el cual la estructura pulsional, la conciencia y el mundo exterior entran en contacto. Toda contraesfera, como lo hace el activismo digital, proyecta intereses, necesidades y condiciones sociales de producción, a través de códigos y repertorios culturales, resultado de una praxis y memoria histórica. La esfera pública proletaria, apuntan ambos autores, es, en esencia comunal. Se trata de la asociación de afectos, basado en la autenticidad, la continuidad, o costumbre, el amor y la solidaridad. De hecho, el videoactivismo, por ejemplo, es básicamente una praxis del pathos, de la conmoción, de la emoción compartida por la acción y el movimiento social, de modo que el acontecer, que por definición es ingobernable, rompe así con la comunicación como dominio en la administración de las emociones inducidas por la industria cultural (Sierra y Montero, 2015), En este sentido, en el paso del plano informacional (o del paradigma de la representación) a la dimensión expresiva, el giro de las emociones en la interpretación de las nuevas formas de protesta y acción colectiva justifican esta mirada, en el sentido de que sin el estudio de las emociones no es posible comprender los procesos de comunicación humana. Y para ello el enfoque marxista de tradiciones heterodoxas como la que aquí se apunta dotan a la teoría crítica de herramientas para la comprensión cabal de los procesos en curso a lo largo y ancho del mundo, comenzando por trascender la tradición positivista de la escuela crítica para prestar atención a dimensiones constituyentes de dichas contraesferas que se oponen a las formas dominantes de mediación. En esta línea, las tesis de EPO parten de la voluntad de superación de una concepción limitada del dominio y opinión pública desde una lectura restrictiva de influencia kantiana. 
En su principal ensayo sobre el Espacio Público Oposicional, Negt critica a Habermas con razón por su idealización teórica del proceso dialógico que enuncia en su teoría de la acción comunicativa ante realidades comunes como la violencia simbólica y las asimetrías que recorren el espacio público real y concreto. "Negt y Kluge no están simplemente reclamándole que su concepto de publicidad burguesa sea excluyente o que funciona meramente como ideal contrafáctico. El problema es que la excesiva formalización y estabilidad impiden la posibilidad de transformación y dejan fuera elementos centrales de la experiencia para dar respuesta únicamente a necesidades e intereses reificados (...) Una red de normas, legitimaciones, delimitaciones, reglas procesuales y separación de poderes que proviene de la esfera pública política, y una vez establecida, toma decisiones que perturban o invalidan el orden de producción burgués" (Roldán, 2017: 69). El problema de la historia y crítica de la Opinión Pública del filósofo alemán es que parte de un falso dualismo entre producción social e interacción comunicativa, entre trabajo y vida. Un dualismo insostenible, si tomamos en serio el discurso crítico de Marx, como ilustra Bolívar Echeverría (1986). De acuerdo con Bisky, "el dualismo que Habermas tiene presente sólo se consigue ocultando estas relaciones de producción. Con este ocultamiento queda libre el camino para relacionar únicamente el trabajo (acción instrumental) con el desarrollo del hombre como ser natural y la interacción (acción comunicativa) únicamente con el desarrollo del hombre como ser social, con el proceso social; ahora bien, con un proceso social del que están (de principio) excluidos la economía y, sobre todo, las relaciones de producción" (Bisky, 1982: 105).

La caja negra, en suma, del concepto de esfera pública en Habermas es una racionalización que termina por anular, de forma idealista, las contradicciones que recorren todo intercambio simbólico o proceso de mediación. Al grado que la propuesta de condiciones de racionalización del diálogo en las formas de comunicación y deliberación ciudadana no se dan, entre otras razones, pese al marco teórico que formula, porque la comunicación está dominada por relaciones de producción y una estructura de control irracional. La liberación de las coacciones institucionales propias de la Administración Comunicativa termina siendo, de este modo, un mero deseo ajeno a las condiciones materiales del mundo del trabajo y la lógica de la reproducción capitalista. Los universales pragmáticos de las condiciones de habla poco pueden hacer ante los dispositivos y lógicas de enunciación que derivan de la subalternidad y estructuración de la lógica de clases. En este punto, "el procedimiento de Habermas es interesante: abstrae de grado en grado hasta que cree haber hallado los universales que constituyen la base de todos los actos discursivos. Pero faltan (porque hizo abstracción de ellos) los sujetos que realizan estos universales. Sencillamente se suponen" (Bisky, 1982: 108). Prevalece una concepción pragmática, lingüística, descarnada. De modo que la validez intersubjetiva de las normas, y su aplicación, trascienden a los sujetos, su historia y posición social. La praxis queda relegada por una concepción de la verdad que, so pretexto de superar las limitaciones de Marx al respecto, termina transitando del positivismo y la determinación a la idealización del intercambio y de la 
comunicación. El problema, en otras palabras, es, como apunta Gurvitch (1970), que separa la acción conectiva de la conciencia colectiva.

No vamos a incidir más, pues no es el objeto del presente artículo, en las críticas a las nociones dominantes en la literatura sobre Esfera Pública, pero conviene señalar, para concluir aquí la tesis de la necesaria relación conceptual entre ambas dimensiones de la mediación, la inconsecuencia práctica, como apunta Bisky, como una práctica común del idealismo comunicacional, del pancomunicacionismo y la idea de comunicación sin dominio, hoy en boga con las nociones de la neutralidad de Internet y la llamada autocomunicación de masas habitual en la literatura especializada sobre la materia. En general, las interpretaciones tecnológicamente deterministas que prevalecen en los estudios sobre ciberactivismo empiezan por dirigirse contra el carácter material de las relaciones de producción latentes, negando la dimensión propietaria de las redes y canales de mediación, así como en general el marco institucional de distribución, producción y consumo de contenidos simbólicos, para terminar, por regla general, hipostasiando la dimensión creativa e indeterminada de la comunicación como proceso instituyente al margen del proceso general de reproducción.

Un problema común en la interpretación de fenómenos como la Primavera Árabe o el $15 \mathrm{M}$ es la ausencia de una fundamentación en términos de economía política, geopolítica y visión materialista del proceso de movilización y acción colectiva que, por influencia de lecturas autonomistas de la cultura, de moda en los ochenta por interpretaciones de las culturas populares desde el giro lingüístico, sea en Laclau o en los Cultural Studies, termina por ser incapaz de capturar y comprender el sentido y las formas magmáticas y latentes de tensión implícitas en todo proceso de transformación social, cuando, de acuerdo con Manuel Castells, los nuevos movimientos ciberactivistas deben ser analizados considerando la crisis económica estructural y de legitimidad.

De México a España, de Egipto a Irán o Brasil, de Chile a Marruecos, la participación de jóvenes en la red de la nueva oleada de descontento tiene lugar en un marco estructural de crisis sistémica. Pensar los frentes culturales y las emergencias de las culturas populares subalternas que tienen lugar en las formas contemporáneas de activismo digital exige, en este sentido, una lectura correlacional e histórica más consistente de los procesos de mediación social a partir de bases teóricas de mayor alcance y criticismo, de mayor potencia reflexiva, más allá de las erupciones e irrupciones visibles, a nivel de la epidermis social.

Desde una perspectiva crítica, sabemos que ni las condiciones de validez del habla ni la racionalización de los intercambios son universales, empezando por el reconocimiento del otro. Por otra parte, el giro lingüístico no puede explicar en sí procesos materiales que tienen que ver con la subjetividad, el cuerpo y el espacio particular de procesos sociales que definen el ser en sus manifestaciones concretas. A decir de Postone, "Habermas (y los Estudios Culturales, en general, añadiríamos 
nosotros) desarrolla una teoría de la lógica interna del desarrollo socio-cultural como un proceso de linguistificación de lo sagrado" poco o nada adecuada a la realidad de las multitudes conectadas (Postone, 2006: 328). La contradicción principal, en fin, atribuible a este tipo de lecturas, se constata entre la lógica abstracta de generalización del concepto de opinión pública y las experiencias concretas y singulares de los grupos subalternos. Se da así una suerte de imposición del lenguaje formal racionalizado frente a la dialógica del sentido común de la experiencia, del lenguaje corporal y la construcción colectiva de formas de reconocimiento que terminan siendo subsumidas y obliteradas en la comprensión de los procesos que tienen lugar en el capitalismo. Ahora bien, sabemos que históricamente no hay mediación social sin dialéctica de la experiencia. Ello implica explorar el plano de la inmanencia con todas sus consecuencias. Si bien Habermas formula una propuesta potencialmente emancipadora a partir de la síntesis y la interacción, la lectura evolucionista que formula de la Opinión Pública es del todo cuestionable. Su lectura positiva y logocéntrica de la producción, o la tecnología, sin historizar o contextualizar radicalmente, limita su alcance en la comprensión del proceso de mediación social. Empezando porque es necesario reconocer que no hay lógica interna universal ni una dinámica empírica similar o equiparable al espacio público de territorios e historias culturales disímiles. "El punto de partida de la crítica de Habermas es pues universal: a pesar de ser social, en su esencia no se conforma cultural, social o históricamente, sino que se fundamenta en el carácter ontológico de la acción comunicativa a medida que se despliega a lo largo del tiempo. El lenguaje ocupa entonces un lugar en la teoría de Habermas directamente análogo al que ocupaba el trabajo en los tipos afirmativos de marxismo tradicional" (Postone, 2006: 329).

El esfuerzo de la Teoría de la Acción Comunicativa por fundamentar una nueva teoría crítica de la sociedad moderna confunde, como resultado, acción comunicativa con diálogo racional y, epistemológicamente, limita la crítica marxiana del dominio público por la pragmática del giro lingüístico. Ahora, cómo podemos explicar la constitución de la esfera pública si no por imposición y antagonismo. La lectura universalista, etnocéntrica, pancomunicacional, diríamos, casa mal con el desarrollo histórico real que puede colegirse de un análisis genealógico de la modernidad. Por otra parte, además, una lectura materialista, y emancipadora, del dominio público no puede ser dicotómica en términos de organización sintáctica. "Al adoptar la forma abstracta de la comunicación mediada por las mercancías como valor principal, este enfoque no permite una teoría de las ideologías seculares o un análisis de los grandes cambios en la conciencia, las normas y los valores que se han sucedido en la sociedad moderna en el curso de los últimos siglos, cambios que no pueden comprenderse simplemente en términos de oposiciones del tipo tradicional y moderno, o religioso y secular" (Postone, 2006: 333). Cabe, a este respecto, formular, con Bolívar Echeverría, una crítica a la teoría de la racionalización cultural de Weber, de la que Habermas es partícipe, por resultar transhistórica. La asunción de esta visión en la Teoría de la Acción Comunicativa limita el alcance, tecnocráticamente, de la crítica de la mediación social al racionalizar y comprender 
la modernidad postliberal en la crisis de la esfera pública por la subsunción de la llamada administración comunicativa, sin considerar otras dimensiones y relaciones sociales igualmente sustantivas para ilustrar el proceso de colonización de los mundos de vida.

Un elemento, a nuestro juicio, nuclear en este punto es problematizar la experiencia social, el acto o proceso de significación que hace posible la reproducción social entre el sistema normativo y la vivencia del sujeto o actor político. Martin Jay critica a Negt y Kluge, en defensa de las tesis de Habermas, por la visión pesimista del concepto de Erfahrung, y la idea de empobrecimiento, además de la sobreestimaciòn de la dimensión expresiva del lenguaje. Si bien, de acuerdo con ambos autores, toda experiencia es al tiempo subjetiva y pública, no hay mediación sin otredad. El concepto de Erfahrung expresa, para ellos, el declive y desintegración de la experiencia de la modernidad y la apertura de formas creativas y autónomas de trabajo. "En síntesis, para la teoría crítica, la experiencia no equivale a la engañosa inmediatez de la vivencia individual, sino la posibilidad utópica, aún en la época de atrofia de la experiencia, de reinventar esa experiencia para todos" (Roldán, 2017: 73).

Como teoría históricamente específica de la mediación social, el enfoque necesario contra Habermas, es una teoría de las modalidades determinadas, de acuerdo con Postone, de la conciencia y la subjetividad. Solo así es posible pensar nuevos fenómenos como la ideología de la tecnopolítica al pensar las relaciones entre activismo, comunicación subalterna y medios convencionales. En la misma línea, el trabajo desplegado por Oskar Negt y Alexander Kluge es del todo relevante en la medida que sitúa el papel de la mediación en el interfaz entre subjetividad rebelde y trabajo vivo. Ambos ponen el campo de la comunicación, la experiencia mediada, a nivel sociocognitivo, y la lógica del valor, desde nuevos parámetros, para comprender la producción social de la comunicación, hoy aplicable al modelo en red que alimenta el activismo digital. Desde este enclave o mirador, podemos perfilar, a nuestro juicio, una nueva agenda de investigación y un marco sólido de interpretación, de los nuevos fenómenos emergentes, llamada por Castells, autocomunicación de masas.

\section{Hacia una teoría materialista del ciberactivismo}

De la comunicación en sí a la mediación social para sí, una crítica, desde la realidad de los grupos subalternos y su praxis emancipadora, pasa, en este marco lógico, por confrontar la racionalización de los mundos de vida que acompañan a los discursos sobre el ágora virtual como nuevo renacimiento de la democracia en esta línea que dibujamos sucintamente. A partir de esta matriz o base conceptual es posible dirimir si el ciberactivismo ha dado lugar o es consecuencia de una nueva cultura política, una nueva subjetividad y forma de acción colectiva, o por el contrario reproduce el imaginario y la lógica institucional del orden reinante. Si la comunicación y el contacto de las multitudes conectadas han dado lugar, en fin, a 
un espacio público antagonista basado en el lenguaje de los vínculos y lo común, conviene explorar y describir las formas concretas de articulación de este espacio público oposicional.

Sabemos que Internet constituye una potente herramienta de solidaridad y co/implicación. A través de las comunidades virtuales se refuerzan los vínculos de pertenencia e identificación desarticuladas por el capitalismo en su fase terminal. La red de redes es, en este sentido, un espacio informal de articulación de procesos de encuentro, de reconocimiento y conciencia en común en la formación de proyectos colectivos. Ahora, hasta qué punto la nueva oleada de movilizaciones y protestas sociales da lugar a nuevas lógicas de transformación del dominio público, qué alcance y dimensiones cabe advertir como realidades singulares en las nuevas formas de tecnopolítica y acción colectiva, si consideramos el contexto históricosocial más general de transformación y desarrollo del nuevo espíritu del capitalismo. No es objeto de este artículo desglosar todos y cada uno de los problemas derivados del nuevo modelo de mediación social a propósito de la discusión que hemos tenido aquí a bien formular. Tomando en cuenta la pertinencia y actualidad de una lectura materialista de los nuevos procesos de mediación social, y a tenor de los considerandos aquí expuestos brevemente para delinear un enfoque marxista de las nuevas formas de producción que acompañan la llamada revolución digital en las derivas activistas de los nuevos movimientos urbanos, vamos a limitarnos al menos a apuntar varias líneas y problemas de investigación que, desde un enfoque materialista, conviene abordar por parte de la teoría crítica de la comunicación.

En el trabajo de campo del proyecto de I+D en el que venimos trabajando, podemos constatar que la comunicación primaria por redes sociales desarrolla nuevas prácticas, modos interpersonales de construcción de la subjetividad distintos a los habituales, empezando por reconocer que dan lugar a formas proyectivas de los imaginarios colectivos de inusitado alcance comparativamente con formas prexistentes de interacción social. Las mediaciones del sentido común y de la pertenencia exigen en consecuencia otra mirada sobre el factum de lo social. Pues, como es aceptado en los estudios sobre acción colectiva, "uno de los rasgos del desarrollo de un movimiento social es que tiende, de facto, a las formas alternativas de apropiación, gestión, organización y dirección de recursos y procesos sociales y políticos. Estas formas alternativas son potenciales armas de lucha dirigidas a incidir en el Estado y en las representaciones de la sociedad civil, sobre la posibilidad de hacer, organizar y dirigir y vivir las cosas de otro modo; la capacidad ya desarrollada por el movimiento para pasar de la crítica a la reorganización de las cosas. Tal como lo expresan los conceptos planteados sobre movimientos sociales emergentes en el mismo contexto histórico, entendemos que la confrontación política adquiere centralidad en la definición misma de los movimientos sociales. La relación que se establece con la instancia estatal es una unidad que encierra el mismo tiempo la interpelación como la apelación en la 
disputa por el acceso a derechos y reconocimientos" (Herrera, Peralta y Díaz, 2017: 80).

Desde el punto de vista de la investigación cabe problematizar a este respecto varias cuestiones, siempre, como hemos venido argumentando, desde una perspectiva materialista y emancipadora: de las necesidades y repertorios de acción colectiva, al dominio de las redes, el tipo de actores políticos, las narrativas y estructuras orgánicas que hacen posible el antagonismo y los repertorios de acción. La cultura digital plantea numerosos problemas de modelo de desarrollo, derechos de acceso, cuestiones de justicia y representación, dilemas teóricos y económicopolíticos, así como discusiones de calado sobre el proceso de reproducción cultural en una fase de mercantilización extrema del conjunto social. De hecho, en virtud de la necesaria crítica antes expuesta a la idea de esfera pública habermasiana, la tecnopolítica contemporánea apunta a la necesidad y pertinencia de: "a) democratizar toda institución sociopolítica que use la publicidad: partidos políticos, mass media y entidades públicas y privadas - tal como hará Wikileaks - ; b) instaurar en ellas libertad de comunicación y discusión, y una publicidad interna y externa entre ellas y la ciudadanía; c) publicitar todas sus actividades, dependencias y vínculos económicos" (Comas, 2012: 126).

La dialéctica de la autogestión y la centralización de la cultura digital se traducen, de hecho, en diversas contradicciones entre espontaneidad y organización centralizada de los nuevos movimientos sociales, entre actualidad y oportunidad y sentido común, entre autoregulación y heterodeterminación, entre expropiación de los bienes comunes y apropiación tecnológica, o entre las dinámicas de integración y cooptación y el antagonismo. En cada una de las experiencias singulares de activismo digital que podemos analizar, con independencia del resultado o resolución del conflicto que tiene lugar con el proceso de intervención, "se configura un hackeo social, tecnológico y cultural incesante, en que el momento de la socialización es más importante que el de la producción, en que el proceso es más importante que los productos y en que el gozo es simultáneo a la realización" (Condorelli y Gambetta, 2016: 7 y 8). A partir de ellos es posible observar distintas formas de antagonismo y autonomía de la comunicación en la nueva tecnocultura, perfilando nuevas formas organizativas por pensar.

En nuestro trabajo de campo, hemos observado cómo el ciberactivismo da lugar a una multiplicidad de nuevas prácticas, formas de mediación y autoorganización social, que, con la proliferación de otro tipo de experiencia en las redes sociales, alteran y reformulan los modelos de reproducción social de referencia en la que se observan lógicas ambivalentes de articulación. Pues "la cibercultura, entendida como el espacio de comunicación e interacción creado por la red Internet, genera en su interior grandes inequidades, exclusiones y ejercicios de poder y dominación a través de las redes de información, pero también (al mismo tiempo) abre una posibilidad a la imaginación y la creatividad social" (Rueda, 2006: 20). A este nivel tenemos pues la cooperación solidaria, la autonomía y praxis mancomunada, y la 
apropiación de los medios y tecnologías. La comunicación participativa debe ser observada, en este sentido, como una lógica de constitución de la multiplicidad y autonomía social. Más que el proceso de apropiación y reconfiguración de la llamada esfera pública, se antoja, a nuestro juicio, más significativas las nuevas articulaciones comunitarias. En este sentido, el ciberactivismo es una suerte de recomposición y ensamblaje de la economía moral de la multitud. De acuerdo con Dean, "los nombres, las tácticas y las imágenes comunes están juntando los fragmentos, haciéndolos legibles como los numerosos frentes de una única lucha contra el capitalismo. Allí donde la proliferación de asuntos e identidades nos dispersa y debilita -propiciando el sarcasmo que glorifica su crítica incluso cuando socava la solidaridad -, los acontecimientos multitudinarios de la última década están forzando un nuevo sentido del poder colectivo. Han hecho que las expectativas de multiplicidad den paso a experiencias de colectividad" (Dean, 2017: 41). En la misma línea, el concepto de apropiación debe ser repensado como una categoría en movimiento, y la investigación, a decir de Jesús Ibáñez, renunciar a la razón sedentaria para procurar la mirada nómada de las redes, espacios e intersticios de producción de lo común. No sólo la investigación social y comunicológica ha de ser, necesariamente, creativa y tomar conciencia de los efectos productivos en la realidad social. En el propio proceso de apropiación, ha de reconocer, por principio, que la gente común desarrolla la capacidad creativa de nuevos usos y significados de los objetos y/o procesos apropiados. En esta voluntad insubordinada, las experiencias de las personas, las formas de mímesis y subversión, tanto en el proceso de apropiación como en la autogestión, no siguen una lógica unívoca, sino que más bien tienen lugar de forma diferente, según los individuos e intereses, del mismo modo que el lenguaje, como Bajtín demostrara, siempre es polisémico en las culturas populares, se asocian, en fin, a diferentes significaciones sociales, vinculadas directamente a una expansión de su uso y a una conformación de prácticas y procedimientos cotidianos que normalmente desbordan las estrategias mercadológicas o burocráticas de programación y definición a priori de la materialidad viva de lo social. Tal enfoque crítico parte de la deconstrucción del mito de la modernidad sobre la ilusión o falsa transparencia de la información como característica principal del proceso de mediación. A nuestro entender, "toda relación de representación se funda en una ficción: la de la presencia a un cierto nivel de algo que, estrictamente, está ausente del mismo. Pero por el hecho mismo de que se trata a la vez de una ficción y de un principio organizado de ciertas relaciones sociales, la representación es el terreno de un juego cuyo resultado no está predeterminado desde el comienzo" (Laclau y Mouffe, 2004: 161). Considerando estos términos, la propuesta de Espacio Público Oposicional, exige explorar los modos propios de comunicación, las estéticas de resistencia, los contornos del espacio público antagonista en sus formas de expresión y autogestión empezando por analizar los patrones de participación, las estructuras organizativas, las formas de protesta y las políticas institucionales de reconocimiento y autonomía en sus manifestaciones singulares, específicas, reales y concretas. 
El nuevo ecosistema informacional plantea la necesidad de discutir en detalle los niveles y formas concretas de la interacción social en procesos de transformación como los protagonizados por los nuevos movimientos urbanos reconociendo el principio de diversidad y la centralidad de las formas singulares de proyección de los actores sociales. Pues la interpenetración de trabajo y vida, lo público y lo privado, la producción y reproducción de lo social atraviesan en distintas lógicas de ambivalencia las nuevas formas de mediactivismo proyectando, sintomáticamente, los signos de transformación de la cultura en nuestro tiempo de forma específica. Ello implica discutir los procesos y metodologías, por ejemplo, de participación de la ciudadanía en espacios institucionales como las webs municipales, así como los modelos de gobernanza y gestión de los intercambios sociales que tienden a reproducir inercias y formas tradicionales de representación. Parafraseando a Luckács, no todo lo nuevo es bueno, no toda innovación es progresiva. La irrupción de las tecnologías de la información en la vida contemporánea debe, por lo mismo, ser cuestionada, desde el punto de vista de la reflexividad social general, en términos de ciencia y sociedad, de modelos orgánicos o de ingeniería social, explorando las nuevas matrices culturales, el discurso público y los proyectos de desarrollo que acompañan a la configuración de las formas permitidas y negadas de mediación a partir del universo de la praxis. Volvemos al dilema de cómo hacer cosas con palabras. "No se trata de la esencia sino del acontecimiento, lo que necesitamos saber no es el es, sino el $y$ : las concatenaciones y movimientos que constituyen una máquina" (Raunig, 2008: 24). Cabe pensar si, como razona Cascio, esta forma de redes sociales participadas es o no un panóptico invertido en la cual la periferia vigila al centro del sistema o, peor aún, es un sistema estricto de clausura y control social expandido, considerando el idealismo comunicacional que acompaña al ciberactivismo, muchos de cuyos movimientos se manifiestan, desde una equívoca cultura libertaria, en términos postpolíticos o incluso manifiestamente antipolíticos como cabía observar en asambleas del 15M. Pero también cabe reconocer en este EPO una suerte de espacio híbrido de política de la inmanencia, desde lo cotidiano y sensible. Esta cultura política de la hibridez y lo compartido es una forma de pensar la transformación en movimiento, en proceso. "Rompen la dicotomía medios/fines. En ellos, el cómo es el qué. El medio, el mensaje. La cuestión no es tanto qué significan, es cómo funcionan. Las masas mediatizadas son flujos comunicativos. No significan nada: son operacionales. Su objetivo, como gusta decir al cineasta Jean-Luc Godard, no es comunicar algo, sino comunicar con alguien. Por ello, la política estriba en el hecho comunicativo mismo: la comunicación no es comunicación para la acción o la movilización políticas, es acción política en sí misma" (Sádaba y Gordo, 2008: 263).

Sabemos, bien es cierto, que el discurrir del tiempo tiene un poder mediador alterativo, modifica el estatuto cultural de los sistemas de representación convirtiendo acciones significativas en mitemas, enmarcando y dotando de sentido los objetos contingentes, y destacando el acontecer, sea trivial o relevante, como un orden mosaico de referencia. Ahora, si queremos comprender esta lógica, cabe advertir que el proceso de intervención a este nivel de la mediación social exige un 
camino de ida y vuelta: de la política a la técnica y de la técnica a la política. De lo contrario, como dijera E.P. Thompson (2002: 16), nos encontramos con las vías muertas, las causas perdidas y el olvido de los propios perdedores en la historia. Por ello es necesario problematizar la economía política y la cultura de innovación social asociada a las nuevas tecnologías y la revolución digital. Ello, a nuestro modo de ver, remite a la praxis y a la dimensión instituyente que tiene la imaginación y los imaginarios, en la estela de las preocupaciones de Castoriadis. Pero no viene al caso explorar aquí la capacitad imaginativa, vinculada a la experiencia, del sujeto político y las clases subalternas en el Espacio Público Oposicional. Simplemente apuntar que este elemento es relevante para comprender la tecnopolítica contemporánea, donde es preciso politizar, críticamente, la generación social de la comunicación y la cultura en una época de creciente disgregación y mercantilización del universo simbólico por las lógicas de mercificación de la innovación tecnológica y social. Separar acción colectiva y comunicación, o reducir la interacción comunicativa en un sentido instrumental como plantean las teorías de recursos impide comprender la forma política del activismo digital en nuestro tiempo. "Si algo ponen en cuestión las flash-mobs en la relación entre comunicación (decir/hablar), identidad (ser) y acción (hacer) es justamente la interpretación bipolar de esta tríada que emplaza, por un lado, la comunicación y las cuestiones de sentido e identidad en un mundo de vida carente de enjundia política y, por otro, la acción y las movilizaciones en un sistema político o una estructura de oportunidad política. Las formas de acción que encontramos en las flash-mobs no responden en exclusiva a una lógica instrumental o puramente racional/cognitiva, ni a una lógica expresiva o performativa. Adoptan más bien la forma de encarnaciones en las que lo social, lo identitario y lo político, de un lado, y la acción y la comunicación, de otro, son, respectivamente, campos y fases indistinguibles" (Sádaba y Gordo, 2008: 256).

\section{Espacio Público y Autonomía Social}

Las nuevas tecnologías de la información favorecen la creación de microespacios públicos, "de secuencias de reciprocidad instantánea de demandas donde pueden surgir nuevas formas de acción colectiva imprevisibles, habida cuenta del carácter intermitente, fluido, de su participación" (Sádaba y Gordo, 2008: 247). La cuestión que plantea las tesis aquí expuestas del EPO es cómo se forma la esfera pública contrahegemónica, cómo germina un espacio autónomo de formación de opiniones desde la periferia y desde abajo a partir de las redes sociales en la construcción de nuevos frentes culturales antagonistas. El análisis de los sistemas de contrainformación, los intercambios de las culturas subalternas o los espacios de discusión y crítica alternativa es definitorio, a nuestro juicio, de la centralidad y proyección del ciberactivismo en los nuevos movimientos urbanos, no tanto porque sean espacios de deliberación y participación popular directa como más bien, entendemos, impugnación de la esfera pública institucionalizada. En otras palabras, el EPO despliega un proceso instituyente de nuevas lógicas de mediación y política en red que cumple una función central en los procesos de cambio entre la lógica de encapsulamiento, la autorreferencialidad, y la baja incidencia social, al margen 
de la esfera mediática dominante, y la ruptura del acontecer y la agenda temática en momentos de intensa movilización y agitación social. Así, "la presencia política de la multitud es disruptiva, rompe con la normalidad institucional y la vida cotidiana de los individuos que la componen. Por una parte, inquieta a quienes están acostumbrados a postularse como sus portavoces, porque su aparición no se predica con sondeos electorales o estudios de audiencias. Ni se neutraliza con campañas y medios convencionales. Y, por otra parte, los individuos y las redes de afinidad que forman la multitud desean retornar al estado de normalidad en cuanto sea posible" (Sampedro, 2005: 303). De acuerdo con las conclusiones del profesor Sampedro:

1. El origen de los nuevos movimientos urbanos se explica por la precariedad del modo de producción dominante. "El capitalismo actual fomenta la movilidad y la flexibilidad, la precariedad de los trabajadores. Necesita de las NTIC para conectar y supervisar a los empleados, coordinar procesos y rebajar costes" (Sampedro, 2005: 290). Pero al tiempo las clases subalternas hacen uso de estas herramientas como espacios de rearticulación de sus demandas y la realización de sus necesidades, como corresponde a la dialéctica de la reproducción social.

2. La acción política de las multitudes conectadas es expresión de estilos de vida conectados y complejos, de un activismo, estéticos y sociales, basado en nuevos principios y formas de organización que se conforman como alternativa en el nuevo horizonte de la revolución digital.

3. La tecnopolítica replica formas de la comunicación como dominio, por ejemplo, la publicidad, al tiempo que es antagonista de la lógica de la mediación institucional haciendo posible la producción de esferas contrahegemónicas.

4. La autonomía, junto al antagonismo, es el principio rector de las prácticas emancipadoras del ciberactivismo.

5. La tecnopolítica es sin embargo inestable, fragmentaria y germinal. No responde a un proyecto o espacio público unívoco como antaño acontecía con el movimiento obrero.

6. La protesta social en los nuevos movimientos urbanos es sobre todo una comunicación social expresiva más que representacional.

7. La ambigüedad es la norma, por lo mismo, más que la excepción en el ciberactivismo.

8. La política de representación y la visibilidad es el principal objetivo de la movilización que promueve el activismo digital de los nuevos movimientos urbanos.

9. Las multitudes conectadas combinan para ello diversas formas variables de intensidad y radicalidad democrática al tiempo que el cálculo de oportunidades de éxito en la movilización.

10. El cambio social, aun siendo el objetivo esencial de este tipo de procesos, puede ser relegado al status quo según prevalezca en el proceso de movilización un sentido pragmático o emancipatorio de la intervención social (Sampedro, 2005: 290-301). 
Considerando la naturaleza del EPO y los datos empíricos recabados en trabajo de campo tanto en Europa como América Latina, la investigación sobre ciberactivismo exige por lo mismo, en coherencia, un abordaje integral desde una perspectiva materialista. Si tuviéramos que destacar, sobre numerosos aspectos susceptibles de ser abordados a partir de las hipótesis aquí expuestas, a nuestro juicio cabe cuando menos señalar cuatro líneas prioritarias de investigación para repensar desde una lectura marxista los procesos emergentes y contrahegemónicos de comunicación en los frentes culturales que acompañan al activismo digital. A saber:

- La lógica estructural de organización.

- La cultura deliberativa de participación ciudadana.

- Los marcos cognitivos y las estéticas de recepción del fenómeno en términos de clase.

- Y los repertorios y formas de intervención social en la práctica de las nuevas formas de acción colectiva.

Todas estas dimensiones son, como argumentamos, cuestiones correlacionadas que no deben ser escindidas en el análisis social. Repensar lo popular y la nueva economía moral de la multitud conectada demanda de la comunicología, según hemos demostrado, otras bases teóricas y conceptuales más consistentes como la que nos brinda la noción de EPO, justo en la medida que el fenómeno del ciberactivismo constituye una realidad que "trata de singularidades conectadas en redes digitales de comunicación distribuida y en redes sociotécnicas metropolitanas ( $y$, con menos intensidad, no urbanas) de transporte, vivienda, educación, salud. Redes que se compenetran, cruzan, atraviesan a lo largo de líneas de fuerza - de visibilidad y de enunciación - que configuran lo visible y lo decible, al tiempo que trazan líneas de fuga y procesos de subjetivación que, al reorganizar las determinaciones dispuestas, escapan a los saberes y poderes que los recorren y moldean" (Condorelli y Gambetta, 2016: 7). Hacerlo, en este sentido, desde una lectura materialista, es la única garantía, sin duda, de poder contribuir a comprender mejor el alcance y naturaleza de los nuevos movimientos de protesta, que atraviesan el ciclo de crisis de acumulación que vive, hoy por hoy, el capitalismo en todo el mundo. De otro modo, la teoría y el estudio de la acción colectiva, no alumbrará sino la descripción de lo mismo en forma superficialmente distinta, a base de la repetición positivista del acontecer como relato de las máquinas de sujeción, que abundan en lo ya vivido, como ilustrara Debord, con el desarrollo de la sociedad de consumo y las fábricas de sueño del Capital. 


\section{Referencias bibliográficas}

BALIBAR, E. (2004): Derecho de ciudad. Cultura y política en democracia. Buenos Aires: Editorial Nueva Visión.

BISKY, L. (1982): Crítica de la teoría burguesa de la comunicación de de masas. Madrid: Ediciones de la Torre.

CASTELLS, M. (2017): Ruptura. La crisis de la democracia liberal. Madrid: Alianza Editorial.

COLEMAN, G. (2014): Hacker, Hoaxer, Whistleblower, Spy: The Many Faces of Anonymous. New York: Verso.

COMAS, M. (2012): El caso Wikileaks como piedra de toque de la democracia deliberativa de Jürgen Habermas. Ilameta, 4 (8), pp. 123-151.

CONDORELLI, A. y GAMBETTA, L. (2016): De la movilización ciberactivista a una biopolítica de las redes. Revita DIXIT, número 25, julio-diciembre.

DEAN, J. (2017): Multitudes y partido. Iruña: Kratakrac.

DÍAZ, I., JOVER, J. y ROCA, B. (2017): Del 15M al giro electoralista. Proyectos espaciales y fetiches políticos en las estrategias de acción colectiva. Cuadernos Geográficos, 56 (1), pp. 344-364.

DOWNING, J. (2001): Radical Media. Rebellious Communication and Social Movements. London: Sage.

ECHEVERRÍA, B. (1986): El discurso crítico de Marx. México: Ediciones ERA.

FUCHS, C. y MOSCO, V. (eds.) (2017): Marx in the Age of Digital Capitalism \& Marx and the Political Economy of the Media. London: Haymarket Books.

GRAU, E. e IBARRA, P. (coords.) (2004): La red en la calle. ¿Cambios en la cultura de movilización? Barcelona: Icaria.

GURVITCH, G. (1970): Dialéctica y Sociología. Madrid: Alianza Editorial.

HERRERA, M.R., PERALTA, M.I. y DÍAZ, R.M. (2017): Movimientos sociales y acceso a bienes y servicios. Propuesta de marco analítico a partir de un análisis comparado de casos: confrontación política de personas desocupadas (Argentina) y ocupación de vivienda (España). Revista Trabajo Social Global - Global Social Work, 7 (12), pp. 69-92. 
LACLAU, E. y MOUFFE, C. (2004): Hegemonía y estrategia socialista. Hacia una radicalización de la democracia. Buenos Aires: FCE.

LÉVI-STRAUSS, C. (2006): Antropología estructural: Mito, sociedad, humanidades. México: Siglo XXI.

LÉVY, P. (2002): Ciberdemocracia. Ensayo sobre filosofía política. Barcelona: UOC.

MODONESI, M. (coord.) (2015): Movimientos subalternos, antagonistas y autónomos en México y América Latina. México: UNAM.

MODONESI, M. (2016): El principio antagonista. Marxismo y acción política. México: ITACA/UNAM.

NEGT, O. (2007): L'espace public oppositionnel. Paris: Editions Payot.

NEGT, O. y KLUGE, A. (1993): Public Sphere and Experience: Toward an Analysis of the Bourgeois and Proletarian Public Sphere. Minneapolis: University of Minnesota Press.

PECOURT, J. (2016): Anoymous y el undergroung digital: aproximación al análisis de un objeto socio-digital. Revista Española de Sociología, v. 25 (1), pp. 133-149.

PERUZZO, C.K. (2016): La comunicación en los movimientos sociales y el Derecho a la Comunicación: señales de un derecho de ciudadanía de quinta generación. Revista COMMONS, 5 (2), pp.8-36.

POSTONE, M. (2006): Tiempo, trabajo y dominación social. Una reinterpretación de la teoría crítica de Marx. Barcelona: Marcial Pons.

RANCIÈRE, J. (2010): El espectador emancipado. Castellón: Ellago Ediciones.

RAUNIG, G. (2008): Mil máquinas. Breve filosofía de las máquinas como movimiento social. Madrid: Traficantes de Sueños.

REGUILLO, R. (2017): Paisajes insurrectos. Jóvenes, redes y revueltas en el otoño civilizatorio. Madrid: Ned Ediciones.

ROLDÁN, E. (2017): Las contraesferas públicas de Kluge y Negt: experiencia, fantasía, utopía. Revista Nómadas, no. 47, pp.65-79.

RUEDA, R. (2006): Apropiación social de las tecnologías de la información: ciberciudadanías emergentes. Tecnología Educativa, ILCE, número 4, México. 
- Francisco Sierra Caballero

SÁDABA, I. y GORDO, Á. (coords.) (2008): Cultura digital y movimientos sociales. Madrid: Libros Catarata.

SAMPEDRO, V. (2005): 13-M Multitudes On-line. Madrid: Catarata.

SIERRA, F. (ed.) (2019): Teoría del Valor, Comunicación y Territorio. Madrid: Siglo $X X I$.

SIERRA, F. y MONTERO, D. (eds.) (2015): Videoactivismo y movimientos sociales. Teoría y praxis de las multitudes conectadas. Barcelona: Gedisa.

SOUSA-SANTOS, B. (2016): La difícil democracia. Una mirada desde la periferia europea. Madrid: Akal.

TARDE, G. (1986): La opinión pública y la multitud. Madrid: Taurus.

THOMPSON, E. P. (2002): Obra esencial. Barcelona: Editorial Crítica. 